\title{
Is programming of glucocorticoid receptor expression by prenatal dexamethasone in the rat secondary to metabolic derangement in adulthood?
}

\author{
Mark E Cleasby, Dawn E W Livingstone, Moffat J Nyirenda, Jonathan R Seckl and Brian R Walker \\ Endocrinology Unit, Department of Medical Sciences, University of Edinburgh, Western General Hospital, Edinburgh EH4 $2 X U$, UK \\ (Correspondence should be addressed to B R Walker; Email: B.Walker@ed.ac.uk)
}

\begin{abstract}
Objective: Glucocorticoids may contribute to the association between retarded growth in utero and insulin resistance in adulthood. Administration of dexamethasone (dex) to pregnant rats results in low birth weight offspring, which develop glucose intolerance, hyperinsulinaemia and hypercorticosteronaemia. This may be explained by tissue-specific differences in expression of glucocorticoid receptors (GR) in adult offspring: GR is increased in visceral fat and liver, and decreased in hippocampus and soleus muscle. However, cause and effect between altered GR expression, hypercorticosteronaemia, and hyperinsulinaemia remains to be established.

Design and methods: Rats were treated with dex $(100 \mu \mathrm{g} / \mathrm{kg}$ per day $)$ or saline during the third week of pregnancy. In 5-8-month-old male offspring, GR expression in insulin target tissues was quantified by RNase protection assay in rats that were adrenalectomised (ADX group), sham operated (SHAM group), or adrenalectomised with supra-physiological corticosterone replacement (CORT group) $(n=7-8$ per group), and in rats treated orally with vehicle, metformin $(43 \mathrm{mg} / \mathrm{kg}$ per day) or rosiglitazone ( $1 \mathrm{mg} / \mathrm{kg}$ per day), after 3 weeks.

Results: Manipulation of corticosterone concentration did not affect GR mRNA in skeletal muscle or adipose. In liver, sham-operated animals showed lower GR mRNA, but there was no difference between adrenalectomised and hypercorticosteronaemic animals (SHAM $0.11 \pm 0.01$ ratio to $\beta$-actin, vs ADX $0.22 \pm 0.02$, CORT $0.23 \pm 0.02$, (values expressed as means \pm S.E.M.), $P<0.001$ ). Rosiglitazone reduced GR mRNA by $\sim 30 \%$ in liver of dex- and saline-treated offspring $(P<0.05)$, but had no effect on GR in adipose and skeletal muscle. Metformin abolished the 38\% up-regulation of liver GR mRNA induced by antenatal dex and also reduced GR mRNA preferentially in muscle of dex-treated animals $(0.14 \pm 0.01$ vs $0.10 \pm 0.01 ; P=0.03)$.

Conclusions: We conclude that neither hypercorticosteronaemia nor hyperinsulinaemia are sufficient to cause the changes in GR expression in dex-programmed rats, implying that these changes may be primary in determining the programmed insulin resistant phenotype. Normalisation of GR expression by metformin may be important in the mode of action of this anti-diabetic agent and may be especially useful to reverse-programmed up-regulation of GR.
\end{abstract}

European Journal of Endocrinology 148 129-138

\section{Introduction}

Numerous epidemiological studies associate poor growth in utero with hypertension (1), glucose intolerance (2), insulin resistance (3), non-insulin-dependent diabetes (2), and ischaemic heart disease in adult life (4). The molecular mechanisms of these associations are not understood, but it is likely that adverse stimuli act during particular developmental time windows during which rapid cell division and/or differentiation is taking place (5). One hypothesis proposed to explain this 'programming' effect is overexposure of the foetus to glucocorticoids (6). Glucocorticoids are important in the development of various organ systems before birth, and elevated glucocorticoid levels during pregnancy are associated with in utero growth retardation $(7,8)$.

The administration of dexamethasone (dex) to pregnant rats results in low birth weight offspring that develop hypertension (9), glucose intolerance, insulin resistance (10), and an overactive hypothalamic-pituitary-adrenal (HPA) axis (11) in later life. These adult manifestations of programming may be explained by tissue-specific differences in expression of glucocorticoid receptors (GR). In the hippocampus, which is key in modulating feedback sensitivity of the HPA axis, 
down-regulation of GR is apparent in dex-treated rats (12), implying reduced negative feedback to the HPA axis, and explaining the hypercorticosteronaemia observed. In the liver, GR is up-regulated (10), specifically in the peri-portal zones in which gluconeogenesis is under positive regulation by glucocorticoids (13). Increased hepatic glucose output is the likely result. Plasma glucose levels are also determined by peripheral disposal to skeletal muscle and adipose tissue. Recently, in adult rats prenatally exposed to dex, we found that GR mRNA is also selectively increased in visceral adipose tissue, but not in either subcutaneous adipose tissue or in skeletal muscle; indeed in the soleus muscle (mainly type 1 oxidative fibres) GR mRNA levels are reduced (14). GR in visceral adipose is important for glucose uptake and metabolic homeostasis, which may be pertinent to the insulin-resistant hyperglycaemic phenotype (15). However, the mechanism(s) underlying these tissue-selective changes in GR density in key metabolic tissues remain unclear.

Previous in vivo studies have shown that short-term increases in glucocorticoid levels down-regulate GR mRNA in liver $(16,17)$ and skeletal muscle (18), while adrenalectomy up-regulates GR mRNA in muscle (19), but not in liver (17). However, there is very little published information documenting GR auto-regulation in adipose tissue, or the effects of chronically altered glucocorticoid levels on GR. Thus, a key question is whether the observed changes in GR are of primary importance in determining the adult phenotype of prenatal dex-programmed rats, or whether altered GR expression is merely secondary to their hypercorticosteronaemia. It is possible that hyperinsulinaemia could also affect GR expression, since insulin sensitivity has been inversely correlated with GR expression in insulin resistance (20), and cAMP levels are known to affect GR mRNA stability (21). A second question, then, is whether changes in GR expression in dex offspring are secondary to their insulin-resistant phenotype.

In this paper, we examine whether the observed tissue-specific changes in GR expression in adult offspring of dams administered dex prenatally are permanent, or can be attenuated by manipulation of the HPA axis or insulin sensitivity. In experiments in adult offspring, we altered the concentration of circulating corticosterone, or administered insulin-sensitising drugs (metformin or rosiglitazone), and examined the resulting level of GR expression in primary insulin target tissues.

\section{Materials and methods}

\section{Maintenance and prenatal treatment of animals}

Nulliparous 200-250 g female Wistar rats were maintained under controlled lighting (lights on 0700-
$1900 \mathrm{~h})$ and temperature $\left(22^{\circ} \mathrm{C}\right)$, provided with food (Standard rat chow, Special Diet Services, Witham, Essex, UK) and water, and allowed to feed ad libitum. They were time-mated on day 0 of pregnancy, and littered on day 22. Pregnant females were injected subcutaneously with $100 \mu \mathrm{g} / \mathrm{kg}$ dex in $0.9 \%$ saline containing $4 \%$ ethanol (Dex mothers) or $1 \mathrm{ml}$ per $\mathrm{kg}$ vehicle (Saline mothers) each morning on days 1521 of pregnancy inclusive. Pups were weighed after birth, and litters culled to eight, retaining males in preference. After weaning at 3 weeks, male offspring were kept in cages containing sibling pairs (corticosterone experiment) or in groups of four (insulin-sensitising experiment). Experimental cohorts contained a maximum of two male offspring per litter, selected randomly. All animal procedures were carried out under the terms of the UK Animals (Scientific Procedures) Act 1986.

\section{Manipulation of plasma corticosterone}

Dex offspring underwent bilateral surgical adrenalectomy (ADX group), adrenalectomy plus subcutaneous corticosterone pellet implantation (CORT group), or sham surgery (SHAM group) at 8 months. Adrenalectomy or sham surgery was performed through paralumbar incisions under halothane anaesthesia. Adrenalectomised rats were maintained subsequently on $0.9 \%$ saline. After 3 weeks, $n=6-8$ animals per sub-group were killed by decapitation between 0900 and $1100 \mathrm{~h}$, organs were weighed, and trunk plasma and tissues frozen at $-80^{\circ} \mathrm{C}$. Fat was removed from the subcutaneous (prefemoral) and retroperitoneal (perirenal) depots.

Corticosterone 21-acetate pellets consisting of a 2:1 mixture of corticosterone 21-acetate with elastomer (Silastic 20 medical grade, Dow Corning Corp., Midland, MI, USA) were prepared as previously described (22). Such pellets have been demonstrated to release corticosterone at a constant rate for 4 weeks (22). In a preliminary experiment, pellets were incubated in $0.9 \%$ saline, and the quantity of hormone released estimated spectrophotometrically at $240 \mathrm{~nm}$. Five pellets were implanted, calculated to release a total of $0.6-0.7 \mathrm{mg}$ corticosterone over $24 \mathrm{~h}$.

\section{Administration of insulin-sensitising drugs}

Adult offspring of dex and saline-treated dams were given insulin-sensitising drugs dissolved in water, or water alone, by gavage from 5 months of age. Eight animals per sub-group received $1 \mathrm{mg} / \mathrm{kg}$ rosiglitazone (ROS group), $43 \mathrm{mg} / \mathrm{kg}$ metformin (MET group), or $1 \mathrm{ml} / \mathrm{kg}$ water (VEH group) daily, at $0900 \mathrm{~h} \mathrm{(23).}$ During this period, animals were weighed on alternate days, and food intake per cage (four individuals) was measured daily. Animals were killed after 3 weeks' treatment, as described above. 


\section{Plasma corticosterone assay}

Freshly thawed plasma was used for the analysis of corticosterone, using a specific radioimmunoassay, modified for use in a microtitre plate scintillation proximity assay (Amersham Pharmacia Biotech, Little Chalfont, Buckinghamshire, UK) (24). The lower limit of accurate detection for this assay was $50 \mathrm{nmol} / \mathrm{l}$. Polyclonal rabbit anti-corticosterone antibody was kindly provided by Dr Chris Kenyon, University of Edinburgh.

\section{Isolation of RNA}

RNA was isolated from tissues using TriZol (Invitrogen Life Technologies/Gibco BRL, Paisley, UK). Muscle was powdered using a pestle and mortar under liquid nitrogen, while liver and adipose tissue were homogenised (Ultra-Turrax T8 auto-homogeniser, Ika Labortechnik, Staufen, Germany). For adipose tissue, homogenates were centrifuged at $600 \boldsymbol{g}$ for $10 \mathrm{~min}$ and the lipid supernatant discarded. The integrity of total RNA was assessed using ethidium bromide after agarose gel electrophoresis.

\section{DNA templates}

Promega Ltd, Southampton, Hants, UK supplied all enzymes and cold nucleotides. pGEM-T Easy vector containing a $186 \mathrm{bp}$ length of rat GR exon 2, derived by $5^{\prime}$-RACE PCR from rat thymus RNA (25), was provided courtesy of Dr Karen Chapman, University of Edinburgh. After linearisation with NCo-I, the complementary antisense RNA strand was generated using SP6 RNA polymerase.

p-TRI-B-Actin-125-Rat plasmid containing a rat $\beta$-actin DNA insert was purchased from Ambion Inc., Austin, Texas, USA, linearised using BamHI, and transcribed using SP6 polymerase. Due to a base mis-match, RNase digestion results in the generation of a $106 \mathrm{bp}$ hybrid, rather than the advertised $125 \mathrm{bp}$. Century RNA size markers (100, 200, 300, 400 and $500 \mathrm{bp}$ ), obtained from Ambion Inc., were labelled with T7 RNA polymerase.

\section{RNA probes}

Riboprobes and markers were synthesised using $\left[\alpha^{32} \mathrm{P}\right]$ GTP $(111 \mathrm{TBq} / \mathrm{mmol}$, Amersham Pharmacia Biotech) (25), with cold rGTP added according to the desired specific activity. For assay of liver, quadriceps and extensor digitorum longus muscle (EDL) GR, $12.5 \mu \mathrm{mol} / \mathrm{l}$ cold $\mathrm{rGTP}$ was used for each probe; for soleus, $12.5 \mu \mathrm{mol} / \mathrm{l}$ for actin and $6.25 \mu \mathrm{mol} / \mathrm{l}$ for GR probes; for adipose tissue, $62.5 \mu \mathrm{mol} / \mathrm{l}$ for actin and $4.17 \mu \mathrm{mol} / \mathrm{l}$ for GR probes. DNA was removed using DNase, and labelled riboprobes and markers were purified by passage through Nick Sephadex G-50 DNA columns (Amersham Pharmacia Biotech). Aliquots of each probe were electrophoresed, and their integrity determined using a phosphorimager (FLA-2000, Raytest Scientific Ltd, Sheffield, UK).

\section{RNase protection assay (RPA)}

RNase protection assays (RPAs) were carried out as previously described (25), except for the following details. Hybspeed RPA kits (Ambion Inc.) were used, along with a mixture of RNases $\mathrm{A}(0.5 \mathrm{u} / \mu \mathrm{l})$ and $\mathrm{T}_{1}$ (8 Kunitz units/ $\mu \mathrm{l}$ ) from the kit, or Roche Diagnostics Ltd, Lewes, East Sussex, UK, diluted 1:10. Total RNA $(50 \mu \mathrm{g}$ for liver and quadriceps, $30 \mu \mathrm{g}$ for EDL and soleus, and $25 \mu \mathrm{g}$ for adipose tissue) was co-precipitated with cRNA probe (liver and muscle: GR 100000 c.p.m., actin 250000 c.p.m.; adipose: 150000 c.p.m. of each probe). RNA products were separated on a $4 \%$ polyacrylamide gel containing $7 \mathrm{~mol} / \mathrm{l}$ urea, alongside radiolabelled markers and controls. Results were visualised by autoradiography and quantified using a phosphorimager and Aida 2.0 Auto Image Data Analyser software (Raytest Scientific Ltd). Comparison of the relative abundance of GR mRNA between treatment groups was made after normalisation of GR to actin band intensity. On each gel, duplicate or triplicate reaction products of a standard total RNA preparation were also loaded, and used to normalise data where there was inter-gel variation in relative band intensity.

\section{Statistics}

All data are presented as means \pm S.E.M. Normally distributed data were analysed using one-way (adrenalectomy experiment) or two-way (insulin sensitisation experiment) ANOVA. Post hoc analysis utilised Tukey's Honest Significant Difference or Student's $t$-tests. Kruskal-Wallis ANOVA on ranks was used where data were not normally distributed, with post hoc analysis using Dunn's test. Data relating only to prenatal treatment were analysed using Student's $t$-test, the Mann-Whitney Rank Sum Test or the Chi-square test, as appropriate. Results were taken to be significant with $P \leq 0.05$.

\section{Results}

\section{Birth data}

Analysis of the entire birth cohort showed that prenatal dex treatment reduced birth weight by an average of $15.2 \%$ (control $6.04 \pm 0.05 \mathrm{~g}, n=83$ vs DEX $5.12 \pm$ $0.04 \mathrm{~g}, n=162 ; P<0.001)$. There was no effect of dex on either litter size (control 9.2 $\pm 0.7, n=16$; DEX $10.1 \pm 1.0, n=9$; $P=0.43$ ) or sex distribution (control 47 male, 36 female; DEX 72 male, 90 female; $\left.\chi^{2}=3.46\right)$ 


\section{Effect of modifying plasma corticosterone levels in adult dex offspring}

To determine whether chronic alterations in glucocorticoid levels may explain the tissue-specific differences in GR gene expression seen in dex offspring, adults were adrenalectomised with and without corticosterone replacement.

Plasma corticosterone concentration Trunk plasma corticosterone concentration was below the detection limit $(50 \mathrm{nmol} / \mathrm{l})$ in all ADX rats. Trunk blood plasma corticosterone levels were similar in SHAM and CORT rats (Fig. 1), and elevated relative to the normal circadian mean $(26,27)$.

Body and organ weight There was no difference in the body weight between groups at the end of the experiment (ADX 470 $\pm 14 \mathrm{~g}$, SHAM 513 $\pm 35 \mathrm{~g}$, CORT $492 \pm 31 \mathrm{~g} ; n=7$ or 8 per group; $P=0.29$ ). Thymus mass decreased as the plasma corticosterone concentration increased (Fig. 2), confirming expected chronic effects of surgery with and without glucocorticoid replacement (28).

GR mRNA in tissues In the liver, ADX and CORT rats had similar levels of GR mRNA expression in rats prenatally exposed to dex (Fig. 3a), but levels were twofold higher than in liver from SHAM rats. Chronic glucocorticoid manipulations had no effect on GR mRNA in skeletal muscle (either EDL or soleus, Fig. 3b, c) or adipose tissue (either subcutaneous or retroperitoneal, Fig. 3d, e); in these tissues, sham-operated controls were similar to ADX and CORT-replaced groups.

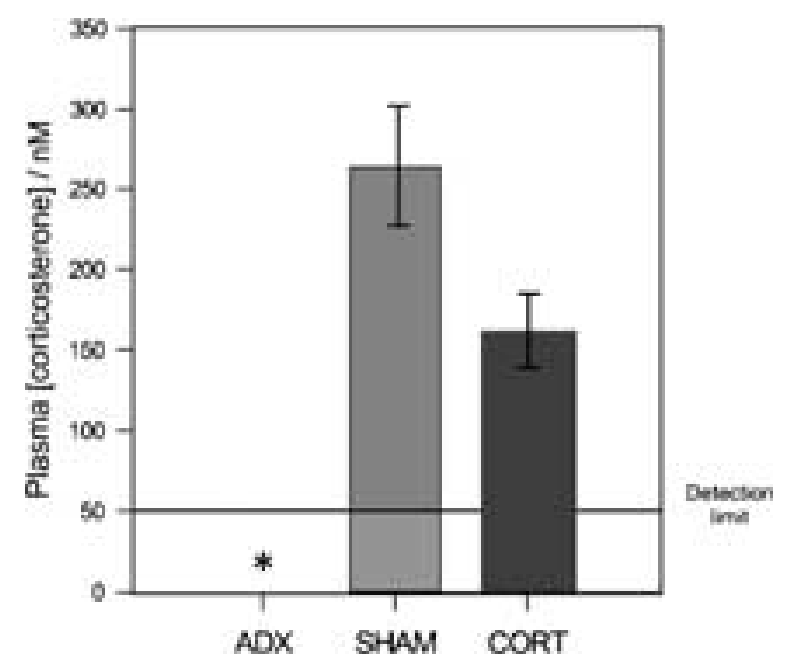

Figure 1 Plasma corticosterone concentration in trunk blood of adrenalectomised (ADX group), sham-operated (SHAM) and adrenalectomised, corticosterone-replaced (CORT) rats. Data are means \pm S.E.M. Overall effect by ANOVA: $P<0.001$. Post hoc: ${ }^{\star} P<0.05$ vs SHAM

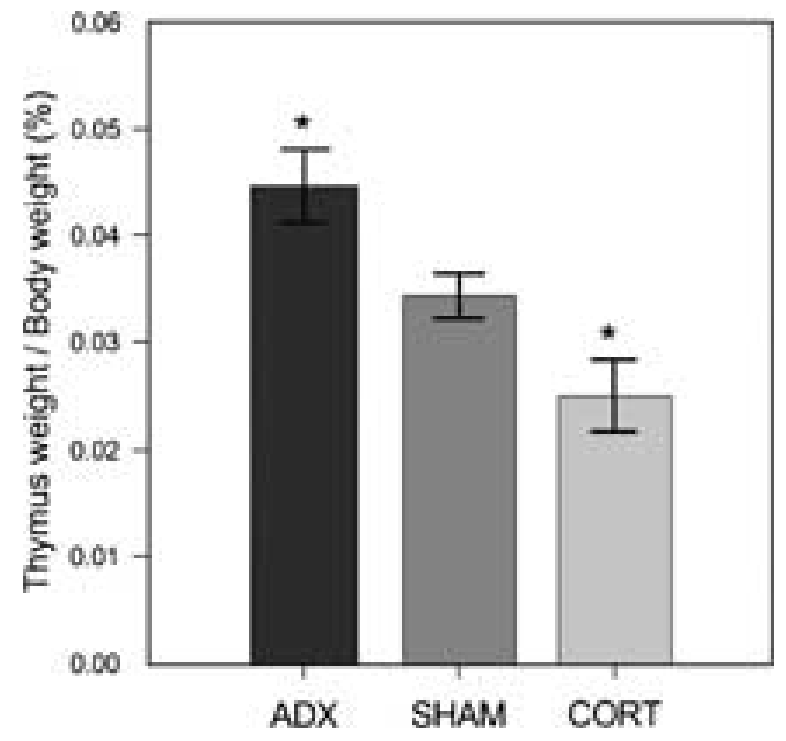

Figure 2 Mass of thymus from adrenalectomised (ADX group), sham-operated (SHAM) and adrenalectomised, corticosteronereplaced (CORT) rats, expressed as a percentage of body mass. Data are means \pm S.E.M. Overall effect by ANOVA, $P<0.001$. Post hoc: ${ }^{\star} P<0.05$ vs SHAM.

\section{Effect of treatment of adults with insulin- sensitising drugs}

To examine the possible role of the documented insulin resistance in this model in producing the changes in GR expression, we exploited two classes of insulin-sensitising drugs.

Body weight/appetite Examination of all 24 rats utilised from each of the two prenatal treatment groups revealed that dex offspring were heavier at the start (Saline 296.5 $\pm 3.3 \mathrm{~g}$, Dex 322.5 $\pm 6.4 \mathrm{~g} ; P=0.003$ ) and end of the experiment, and indeed gained more weight during this period. The administration of insulin-sensitising drugs did not alter body weight gain (Table 1). Dex offspring consumed more chow than controls, while treatment with both metformin and rosiglitazone resulted in a further increase in appetite.

GR mRNA in tissues Prenatal exposure to dex during the third week of pregnancy resulted in a $38 \%$ increase in liver GR mRNA expression in adulthood (Fig. 4a), confirming previous in situ hybridisation data (10), but using RPA methodology. A sample gel is presented in Fig. 5. Rosiglitazone reduced GR mRNA expression in liver independently of prenatal treatment. In striking contrast, metformin reduced GR mRNA levels preferentially in liver of dexprogrammed animals, and thus abolished the difference in liver GR levels between offspring exposed to dex and vehicle prenatally. 


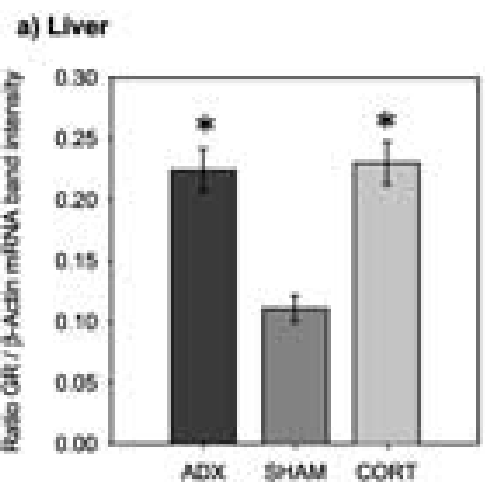

b) EDL

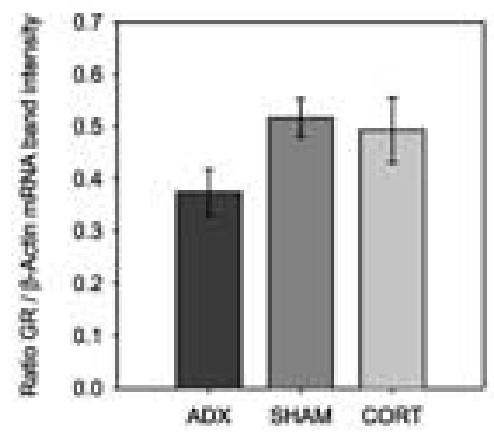

d) Subcutaneous fat

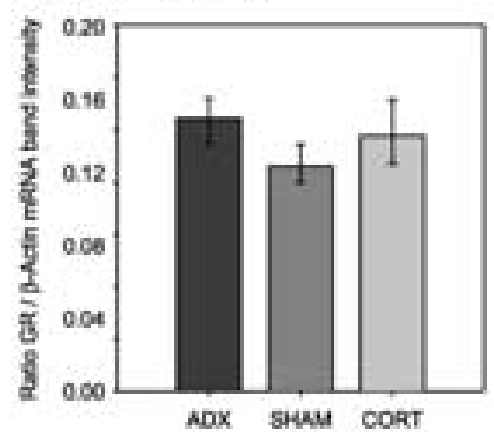

c) Soleus

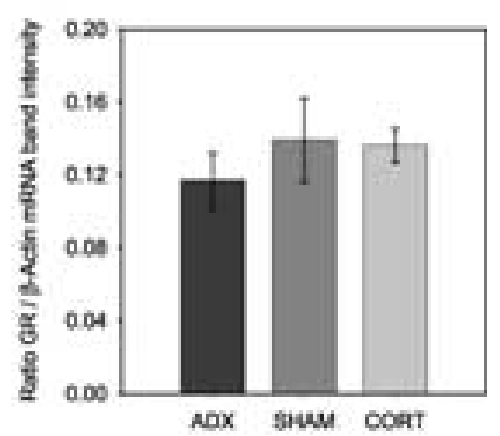

o) Retroperitoneal fat

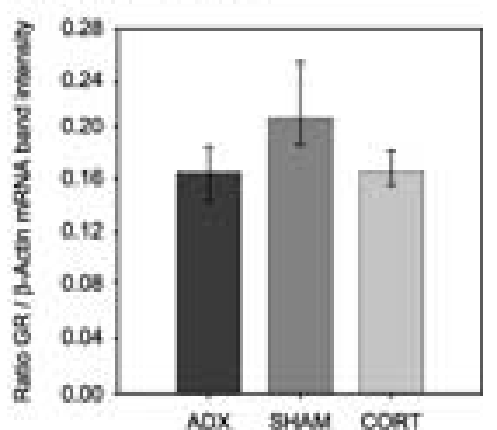

Figure 3 GR mRNA expression in tissues of adrenalectomised (ADX group), sham-operated (SHAM) and adrenalectomised, corticosterone-replaced (CORT) rats, normalised to

$\beta$-actin mRNA. (a) Liver, (b) extensor digitorum longus muscle (EDL), (c) soleus muscle, (d) subcutaneous fat, (e) retroperitoneal fat. Data are means \pm S.E.M. By one-way ANOVA, groups were different in liver only $(P<0.001)$. Post hoc: ${ }^{*} P<0.05$ vs SHAM.

Table 1 Effects of insulin-sensitising drugs on food intake and body weight. Data are means \pm S.E.M. By two-way ANOVA, both prenatal $(P<0.001)$ and adult $(P<0.001)$ treatment had effects on appetite. Both metformin $(P<0.05)$ and rosiglitazone $(P<0.05)$ increased appetite, independent of prenatal treatment. ${ }^{*} P<0.05$ vs prenatal control. Drug treatment had no effect on weight gain during, or body weight at the end of, the experiment. A difference due to prenatal treatment was maintained, however $(P<0.001)$, with dex-treated offspring continuing to gain more weight during this peroid $(P<0.001)$.

\begin{tabular}{llcc}
\hline Treatment group & & $\begin{array}{c}\text { Mean food intake } \\
\text { per cage (g/day) }\end{array}$ & $\begin{array}{c}\text { Mean weight gain during } \\
\text { experiment }(\mathrm{g})\end{array}$ \\
\hline Prenatal & Adult & $157 \pm 4$ & $24 \pm 2$ \\
Saline & VEH & $172 \pm 3$ & $26 \pm 3$ \\
Saline & MET & $168 \pm 3$ & $22 \pm 4$ \\
Saline & ROS & $162 \pm 2$ & $29 \pm 2$ \\
Dex & VEH & $175 \pm 2$ & $35 \pm 2$ \\
Dex & MET & $187 \pm 2$ & $33 \pm 3$ \\
Dex & ROS & & $318 \pm 9$ \\
\hline
\end{tabular}


a) Liver

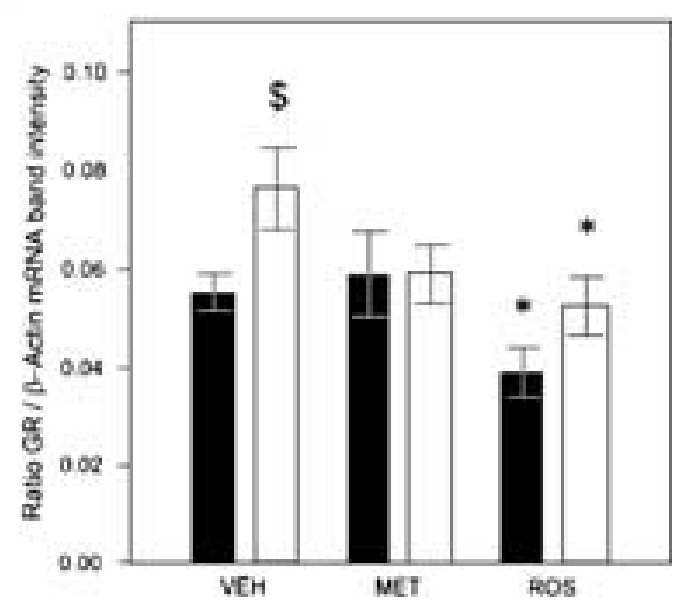

b) Quadriceps

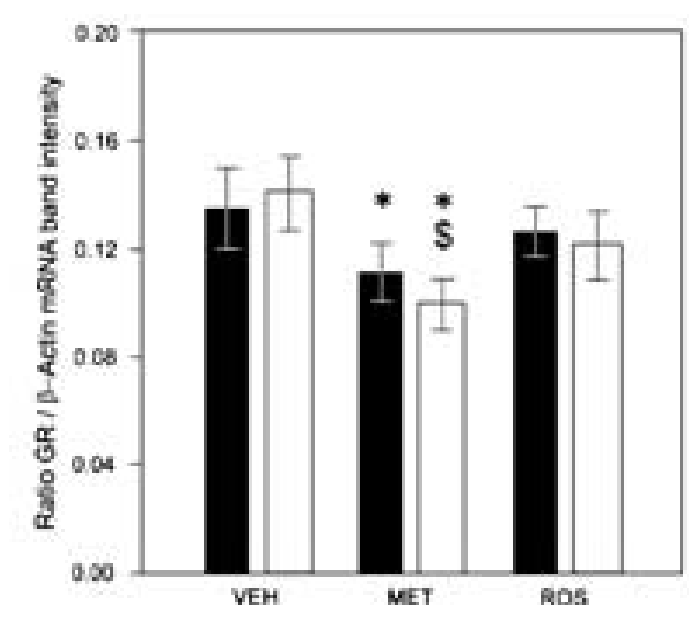

Figure 4 GR mRNA expression in tissues of rats treated with vehicle (VEH group), metformin (MET) or rosiglitazone (ROS). Data are means \pm S.E.M. of ratios against $\beta$-actin mRNA. Black bars = saline, white bars = dex-treated offspring. (a) Liver; by two-way ANOVA, an effect of prenatal $(P=0.043)$ and postnatal treatment $(P=0.018)$ was shown. Post hoc: ${ }^{*} P<0.05$ vs VEH group. $\$ P<0.04$ vs prenatal control. (b) Quadriceps; by two-way ANOVA, effect of adult treatment $(P<0.04)$ but not prenatal treatment was shown. Post hoc: ${ }^{\star} P<0.05$ vs VEH group. $\$ P<0.03$ vs Saline-VEH.

In quadriceps muscle, no significant effect of prenatal treatment on adult GR mRNA levels was seen (Fig. 4b). There was no effect of rosiglitazone administration on GR mRNA, but in contrast, metformin reduced GR mRNA levels in skeletal muscle. Once again, this was predominantly an effect in prenatally dex-programmed animals: there was a significant $29 \%$ reduction in GR mRNA in Dex-MET vs Dex-VEH rats, while the reduction in Saline-MET vs Saline-VEH rats was not significant.

\section{Discussion}

We have shown that in adult rats prenatally exposed to dex, GR mRNA expression in skeletal muscle and adipose tissue is unaffected by chronic manipulation of plasma corticosterone levels. In liver, GR mRNA appeared to be down-regulated by acute stress in sham-operated animals, but was unaffected in all groups by chronic differences in plasma corticosterone. In contrast, treatment of dex-treated offspring with metformin in adulthood normalised GR expression in liver and muscle. These effects were not seen with another insulin-sensitising drug, rosiglitazone, which reduces liver but not muscle GR irrespective of prenatal treatment. This suggests that insulin resistance/hyperinsulinaemia is not of itself responsible for up-regulation of GR expression in programmed animals. Further investigation of the action of metformin on GR regulation may, however, provide key insights into its mechanism of action and the determinants of programming of adult GR expression by prenatal dex. In this paper, we have confined our investigations to the effects of metabolic manipulation in adulthood upon levels of GR mRNA. Additional work is merited to examine whether changes in mRNA observed are also manifested at the protein level, as post-translational modification represents an additional level of control over GR expression (29).

Consistent with prior observations, dex treatment of rats in week three of pregnancy resulted in a significant reduction in birth weight of the offspring, with no alteration in either litter size or sex distribution of pups $(10,11)$. By 5 months of age, however, dextreated offspring were $9 \%$ heavier than controls, which differs from previous results, where offspring prenatally overexposed to glucocorticoids were of the same weight $(10,30)$, or lighter in adulthood $(24)$. During the 3-week period that food intake was monitored, dex offspring showed a marginal, but significant hyperphagia. This may be the cause of the weight gain, as hyperphagia was found to mediate obesity in the offspring of undernourished dams (31). Further analysis of growth trajectory and body composition of dex-programmed offspring would be interesting in the light of the association between low birth weight and later obesity in other animal models (31) and human populations (32).

The primary outcome in our further investigation of these animals is measurement of GR mRNA. In RPAs, the GR signal was normalised to $\beta$-actin. It is arguable, in view of the widespread transcriptional effects of insulin, that there is no ideal 'housekeeping' gene to which gene expression of any target gene can be normalised. However, we found no systematic differences in actin expression between treatment groups.

Plasma corticosterone concentration was chronically manipulated by adrenalectomy with and without supra-physiological corticosterone replacement to 


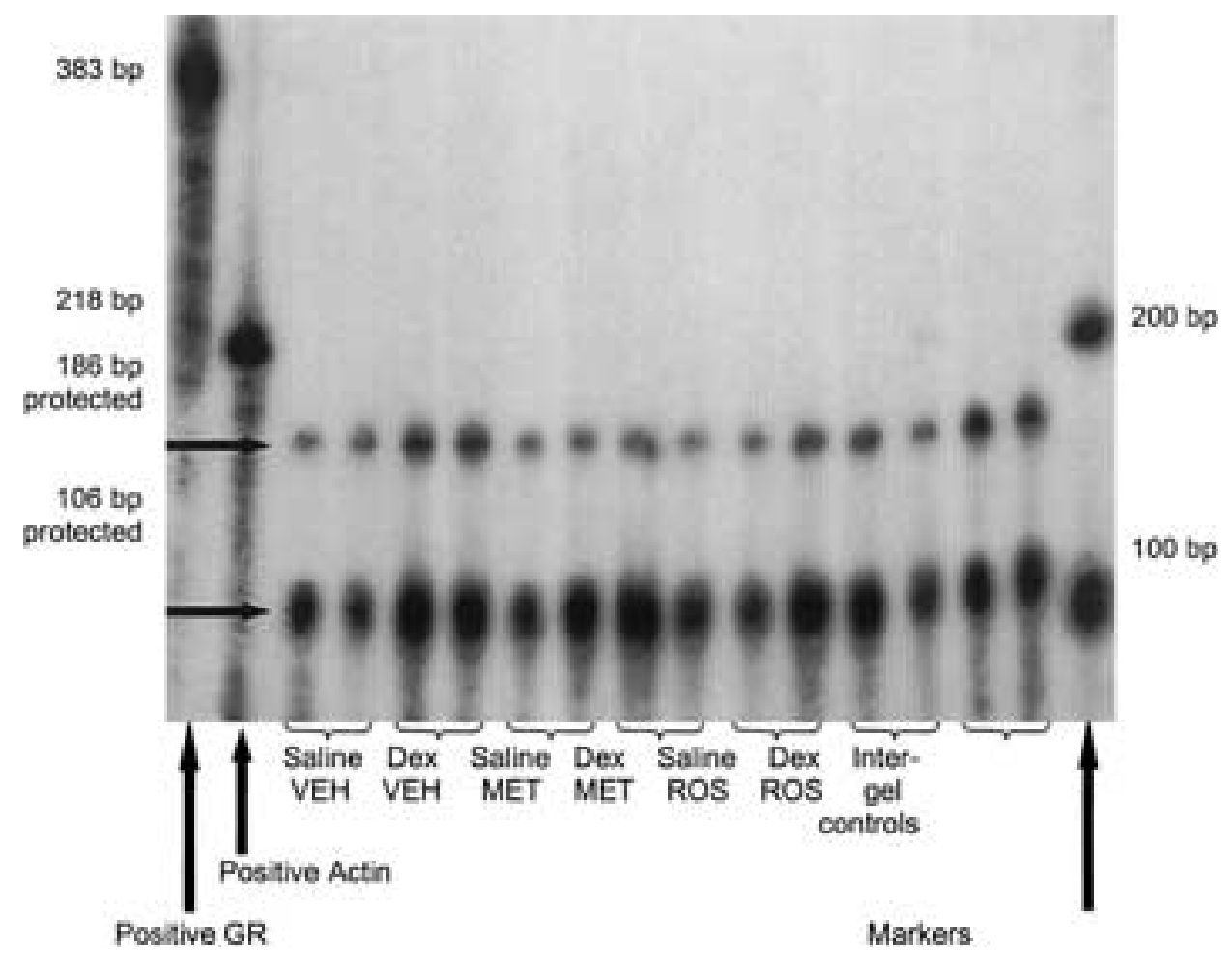

Figure 5 Sample RNase protection gel: assay of GR mRNA in quadriceps muscle of dex- and saline-treated rats, subsequently given insulin-sensitising drugs as adults. The $186 \mathrm{bp}$ and $106 \mathrm{bp}$ bands are specific GR and $\beta$-actin RNA hybrids respectively. Positive control lanes contain full-length riboprobes.

determine whether dysregulation of GR mRNA in the tissues of adult dex offspring is determined by hypercorticosteronaemia. No effect of chronic corticosterone manipulation was seen in either of two different skeletal muscles, the soleus ( $87 \%$ slow twitch, type I, predominantly oxidative muscle fibres) and EDL (98\% fast twitch, type II, mainly glycolytic fibres) (33). Similarly, no effect of altering circulating glucocorticoid was found in either of the white adipose tissue depots tested. In liver, the results were more complex. The primary comparison was made between GR mRNA levels in liver of the CORT and ADX groups, since these represent the extremes of variation in chronic circulating glucocorticoid status; the lack of difference suggests that, as in adipose and muscle, there is no effect of chronic alterations in plasma corticosterone on liver GR mRNA. However, lower GR mRNA was observed in sham-operated animals. This was probably an effect of acute hypercorticosteronaemia, resulting from stress immediately prior to killing, to which adrenalectomised animals would not respond. In support of this contention, liver GR mRNA down-regulation has been recorded previously within $30 \mathrm{~min}$ of administration of dex in vivo (16). Furthermore, an effect of sham surgery per se has been previously identified on the expression in liver of $11 \beta$-hydroxysteroid dehydrogenase type I, the enzyme responsible for re-activation of endogenous glucocorticoid (34). We conclude, therefore, that this relatively large acute effect on GR mRNA expression is not necessarily relevant to chronic effects of corticosterone on GR expression in liver, and that chronic differences in corticosterone do not account for differences in hepatic GR mRNA in dexexposed animals.

Previous studies have not considered the effect of altered corticosterone concentration on GR mRNA in muscles of varying fibre type composition $(18,19)$ or adipose depots, or the effect of such chronic manipulations on liver GR $(16,17)$. However, down-regulation of GR provoked by addition of dex to hepatoma cells reverses within a few days (35), while the effect of adrenalectomy on hippocampal GR is abolished within 2 weeks (36), supporting the implication of this study that GR auto-regulation is a relatively acute phenomenon. These findings indicate that chronic hypercorticosteronaemia is not responsible for tissue-specific dysregulation of GR mRNA levels in dex-programmed rats.

In a separate series of experiments, insulin-sensitising drugs were administered to adult dex-treated and control rats, to evaluate whether normalisation of hyperinsulinaemia would affect programmed GR expression. Metformin and rosiglitazone, two drugs used widely in the clinical treatment of type 2 diabetes, were given using the same protocol as has 
been successfully applied previously to reduce the glucose intolerance and insulin resistance of Zucker obese rats, as assessed by oral glucose tolerance tests (23). The appetite of rats on both of these treatments was stimulated, independent of any programmed effect, but this did not affect weight gain during the course of this experiment. This effect is in contrast to that seen in Zucker obese rats, where appetite was depressed by metformin in one study (37), and unaffected in another (23). Indeed, reduction of food intake and therefore obesity has been suggested to play a role in the clinical effect of metformin (38).

The effects of insulin-sensitising drugs on GR mRNA differed between tissues and between classes of drug. In liver, whereas rosiglitazone reduced GR expression irrespective of prenatal treatment, metformin normalised the programmed over-expression of GR. In skeletal muscle, metformin but not rosiglitazone reduced GR mRNA, again having a greater effect in dex-treated offspring. Thus, the effect of metformin in reducing GR in both tissues is specific to programmed animals, whereas that of rosiglitazone in the liver is non-specific. Some of these changes in gene expression are of small magnitude, so that the ultimate impact of insulin-sensitising agents on GR binding and activation is uncertain. However, of most relevance to the aims of this manuscript, both drugs had similar effects to normalise hyperinsulinaemia (23), yet they did not both normalise GR; we can conclude that GR gene expression in dexprogrammed rats is not determined simply by hyperinsulinaemia. Moreover, programming of GR gene expression in this model appears to be susceptible to a specific, and novel, action of metformin.

Thiazolidinediones, such as rosiglitazone, have antihyperglycaemic effects (39), mediated through binding to peroxisome proliferator-activated receptor gamma $(\operatorname{PPAR} \gamma)$, predominantly in adipose tissue (40). However, PPAR $\gamma$ activation also suppresses hepatic glucose output, despite low levels of receptor expression in the liver (41). It is possible that rosiglitazone has direct effects on the liver, since thiazolidinediones have been shown to modify GR-mediated effects in cell culture (42). However, it is widely supposed that effects on hepatic metabolism are mediated by factors released from adipose tissue that are altered by thiazolidinediones, such as resistin (43), free fatty acids (44) or glucocorticoids (45). Which of these might influence GR expression in liver has not been tested, but this is an important question for further study.

Metformin has well-recorded physiological effects in reducing hyperglycaemia, through insulin-sensitising and non-insulin dependent means (46), but its specific site of action has not been identified. This study shows effects of metformin in reducing GR expression in two insulin-sensitive tissues, most potently in insulinresistant dex-programmed animals. The mechanism of programming of GR mRNA remains obscure, but it has been proposed that its tissue-specificity is explained by differential regulation of alternate promoters influencing transcription at alternate exon 1 start sites (25). The specific effect of metformin on GR mRNA in programmed animals offers a tool to dissect pathways that influence these tissue-specific promoters, which may respond directly or indirectly to metformin, and thereby unravel the molecular mechanism of programming. Equally importantly, down-regulation of GR may be a component of the poorly understood insulinsensitising effect of metformin (20). Moreover, this effect may recommend metformin as an appropriate therapeutic agent for amelioration of the metabolic syndrome in individuals of low birth weight. Further work is required to determine whether the effect of metformin on GR is direct or indirect, whether it is of sufficient magnitude to affect GR function, and hence whether it might be significant in the treatment of diabetes.

In summary, these studies provide evidence that neither hypercorticosteronaemia nor insulin resistance is sufficient to explain all the tissue-specific changes in GR gene expression observed in rats prenatally overexposed to glucocorticoids, implying that GR gene expression is permanently programmed and may be a primary mechanism of insulin resistance. We additionally report that rosiglitazone lowers hepatic GR mRNA independently of programming, which may be important in the hepatic insulin sensitising effect of thiazolidinediones. Finally, we found that metformin reduces GR expression specifically in insulin-resistant liver and muscle, which may offer insights into the molecular determinants of programming of GR and the mechanism of action of this drug.

\section{Acknowledgements}

This work was funded with grants obtained from the Wellcome Trust (MEC, JRS) and the British Heart Foundation (BRW). Thanks are due to Dr Karen Chapman, for advice concerning RPAs, and to Keith Chalmers and June Noble, for expert technical assistance.

\section{References}

1 Barker DJ, Bull AR, Osmond C \& Simmonds SJ. Fetal and placental size and risk of hypertension in adult life. British Medical Journal $1990301259-262$.

2 Hales CN, Barker DJ, Clark PM, Cox LJ, Fall C, Osmond C et al. Fetal and infant growth and impaired glucose tolerance at age 64. British Medical Journal 1991303 1019-1022.

3 Fall CH, Osmond C, Barker DJ, Clark PM, Hales CN, Stirling Y et al. Fetal and infant growth and cardiovascular risk factors in women. British Medical Journal $1995310428-432$.

4 Barker DJ, Winter PD, Osmond C, Margetts B \& Simmonds SJ. Weight in infancy and death from ischaemic heart disease. Lancet $19892577-580$.

5 Widdowson EM \& McCance RA. A review: new thoughts on growth. Pediatric Research $19759154-156$. 
6 Edwards CR, Benediktsson R, Lindsay RS \& Seckl JR. Dysfunction of placental glucocorticoid barrier: link between fetal environment and adult hypertension? Lancet 1993341 355-357.

7 Goland RS, Jozak S, Warren WB, Conwell IM, Stark RI \& Tropper PJ. Elevated levels of umbilical cord plasma corticotropin-releasing hormone in growth-retarded fetuses. Journal of Clinical Endocrinology and Metabolism 199377 1174-1179.

8 Reinisch JM, Simon NG, Karow WG \& Gandelman R. Prenatal exposure to prednisone in humans and animals retards intrauterine growth. Science $1978 \mathbf{2 0 2}$ 436-438.

9 Benediktsson R, Lindsay RS, Noble J, Seckl JR \& Edwards CR. Glucocorticoid exposure in utero: new model for adult hypertension. Lancet $1993341339-341$.

10 Nyirenda MJ, Lindsay RS, Kenyon CJ, Burchell A \& Seckl JR. Glucocorticoid exposure in late gestation permanently programs rat hepatic phosphoenolpyruvate carboxykinase and glucocorticoid receptor expression and causes glucose intolerance in adult offspring. Journal of Clinical Investigation $1998 \quad 101$ 2174-2181.

11 Levitt NS, Lindsay RS, Holmes MC \& Seckl JR. Dexamethasone in the last week of pregnancy attenuates hippocampal glucocorticoid receptor gene expression and elevates blood pressure in the adult offspring in the rat. Neuroendocrinology $1996 \mathbf{6 4} 412-418$.

12 Welberg LA, Seckl JR \& Holmes MC. Prenatal glucocorticoid programming of brain corticosteroid receptors and corticotrophin-releasing hormone: possible implications for behaviour. Neuroscience $2001 \mathbf{1 0 4} 71-79$.

13 Friedman JE, Yun JS, Patel YM, McGrane MM \& Hanson RW. Glucocorticoids regulate the induction of phosphoenolpyruvate carboxykinase (GTP) gene transcription during diabetes. Journal of Biological Chemistry 1993268 12952-12957.

14 Cleasby ME, Walker BR, Kenyon C, Nyirenda M \& Seckl JR. Role of insulin in tissue-specific programming of glucocorticoid receptor expression by prenatal dexamethasone in rats. Proceedings of the American Endocrine Society Meeting 2001 P1-P343.

15 Carter-Su C \& Okamoto K. Effect of insulin and glucocorticoids on glucose transporters in rat adipocytes. American Journal of Physiology $1987252 \mathrm{E} 441-\mathrm{E} 453$.

16 DuBois DC, Xu ZX, McKay L, Almon RR, Pyszcznski N \& Jusko WJ. Differential dynamics of receptor down-regulation and tyrosine aminotransferase induction following glucocorticoid treatment. Journal of Steroid Biochemistry and Molecular Biology $1995 \mathbf{5 4}$ 237-243.

17 Kalinyak JE, Dorin RI, Hoffman AR \& Perlman AJ. Tissue-specific regulation of glucocorticoid receptor mRNA by dexamethasone. Journal of Biological Chemistry 1987262 10441-10444.

18 McKay LI, DuBois DC, Sun YN, Almon RR \& Jusko WJ. Corticosteroid effects in skeletal muscle: gene induction/receptor autoregulation. Muscle Nerve 199720 1318-1320.

19 DuBois DC \& Almon RR. Glucocorticoid sites in skeletal muscle: adrenalectomy, maturation, fiber type, and sex. American Journal of Physiology 1984247 E118-E125.

20 Vestergaard H, Bratholm P \& Christensen NJ. Increments in insulin sensitivity during intensive treatment are closely correlated with decrements in glucocorticoid receptor mRNA in skeletal muscle from patients with Type II diabetes. Clinical Science 2001 $101533-540$.

21 Dong Y, Aronsson M, Gustafsson JA \& Okret S. The mechanism of cAMP-induced glucocorticoid receptor expression. Correlation to cellular glucocorticoid response. Journal of Biological Chemistry $198926413679-13683$.

22 Soro A, Panarelli M, Holloway CD, Fraser R \& Kenyon CJ. In vivo and in vitro effects of carbenoxolone on glucocorticoid receptor binding and glucocorticoid activity. Steroids $199762388-394$.

23 Livingstone DE, Kenyon CJ \& Walker BR. Mechanisms of dysregulation of 11 beta-hydroxysteroid dehydrogenase type 1 in obese Zucker rats. Journal of Endocrinology $2000167533-539$.

24 Welberg LA, Seckl JR \& Holmes MC. Inhibition of 11 beta-hydroxysteroid dehydrogenase, the foeto-placental barrier to maternal glucocorticoids, permanently programs amygdala GR mRNA expression and anxiety-like behaviour in the offspring. European Journal of Neuroscience 200012 1047-1054.

25 McCormick JA, Lyons V, Jacobson MD, Noble J, Diorio J, Nyirenda $M$ et al. 5'-heterogeneity of glucocorticoid receptor messenger RNA is tissue specific: differential regulation of variant transcripts by early-life events. Molecular Endocrinology 2000 14 506-517.

26 Dallman MF, Strack AM, Akana SF, Bradbury MJ, Hanson ES, Scribner KA et al. Feast and famine: critical role of glucocorticoids with insulin in daily energy flow. Frontiers in Neuroendocrinology $199314303-347$

27 Nyirenda MJ, Welberg LA \& Seckl JR. Programming hyperglycaemia in the rat through prenatal exposure to glucocorticoids fetal effect or maternal influence? Journal of Endocrinology 2001 $170653-660$

28 Akana SF, Cascio CS, Shinsako J \& Dallman MF. Corticosterone: narrow range required for normal body and thymus weight and ACTH. American Journal of Physiology 1985249 R527-R532.

29 Dong Y, Poellinger L, Gustafsson JA \& Okret S. Regulation of glucocorticoid receptor expression: evidence for transcriptional and posttranslational mechanisms. Molecular Endocrinology 19882 $1256-1264$.

30 Lindsay RS, Lindsay RM, Waddell BJ \& Seckl JR. Prenatal glucocorticoid exposure leads to offspring hyperglycaemia in the rat: studies with the 11 beta-hydroxysteroid dehydrogenase inhibitor carbenoxolone. Diabetologia 199639 1299-1305.

31 Vickers MH, Breier BH, Cutfield WS, Hofman PL \& Gluckman PD. Fetal origins of hyperphagia, obesity, and hypertension and postnatal amplification by hypercaloric nutrition. American Journal of Physiology: Endocrinology and Metabolism 2000279 E83-E87.

32 Ong KK, Ahmed ML, Emmett PM, Preece MA \& Dunger DB. Association between postnatal catch-up growth and obesity in childhood: prospective cohort study. British Medical Journal $2000320967-971$.

33 Armstrong RB \& Phelps RO. Muscle fiber type composition of the rat hindlimb. American Journal of Anatomy 1984171 259-272.

34 Jamieson PM, Chapman KE \& Seckl JR. Tissue- and temporalspecific regulation of 11 beta-hydroxysteroid dehydrogenase type 1 by glucocorticoids in vivo. Journal of Steroid Biochemistry and Molecular Biology 199968 245-250.

35 Okret S, Poellinger L, Dong Y \& Gustafsson JA. Down-regulation of glucocorticoid receptor mRNA by glucocorticoid hormones and recognition by the receptor of a specific binding sequence within a receptor cDNA clone. PNAS 198683 5899-5903.

36 Holmes MC, Yau JL, French KL \& Seckl JR. The effect of adrenalectomy on 5-hydroxytryptamine and corticosteroid receptor subtype messenger RNA expression in rat hippocampus. Neuroscience $199564327-337$

37 Rouru J, Huupponen R, Pesonen U \& Koulu M. Subchronic treatment with metformin produces anorectic effect and reduces hyperinsulinemia in genetically obese Zucker rats. Life Sciences 199250 1813-1820.

38 Lee A \& Morley JE. Metformin decreases food consumption and induces weight loss in subjects with obesity with type II non-insulin-dependent diabetes. Obesity Research 19986 47-53.

39 Anil KK \& Marita AR. Troglitazone prevents and reverses dexamethasone induced insulin resistance on glycogen synthesis in 3T3 adipocytes. British Journal of Pharmacology $2000 \mathbf{1 3 0}$ $351-358$.

40 Guerre-Millo M, Gervois P, Raspe E, Madsen L, Poulain P, Derudas $\mathrm{B}$ et al. Peroxisome proliferator-activated receptor alpha activators improve insulin sensitivity and reduce adiposity. Journal of Biological Chemistry 2000275 16638-16642.

41 Kimura M, Daimon M, Tominaga M, Manaka H, Sasaki H \& Kato T. Thiazolidinediones exert different effects on insulin resistance between dexamethasone-treated rats and Wistar fatty rats. Endocrine Journal $2000 \mathbf{4 7} 21-28$.

42 Johnson TE, Vogel R, Rutledge SJ, Rodan G \& Schmidt A. Thiazolidinedione effects on glucocorticoid receptor-mediated gene transcription and differentiation in osteoblastic cells. Endocrinology $19991403245-3254$ 
138 M E Cleasby and others

43 Steppan CM, Bailey ST, Bhat S, Brown EJ, Banerjee RR, Wright CM et al. The hormone resistin links obesity to diabetes. Nature 2001 409 307-312.

44 Rebrin K, Steil GM, Mittelman SD \& Bergman RN. Causal linkage between insulin suppression of lipolysis and suppression of liver glucose output in dogs. Journal of Clinical Investigation 199698 $741-749$.

45 Masuzaki H, Paterson J, Shinyama H, Morton NM, Mullins JJ, Seckl JR et al. A transgenic model of visceral obesity and the metabolic syndrome. Science $20012942166-2170$.
EUROPEAN JOURNAL OF ENDOCRINOLOGY (2003) 148

46 Wiernsperger NF \& Bailey CJ. The antihyperglycaemic effect of metformin: therapeutic and cellular mechanisms. Drugs 1999 58 (Suppl 1) 31-39.

Received 16 May 2002

Accepted 7 October 2002 